\section{POS0739 DEVELOPMENT OF A CONCEPTUAL MODEL TO UNDERSTAND DISEASE BURDEN IN PATIENTS WITH SYSTEMIC LUPUS ERYTHEMATOSUS AND LONG- TERM ORGAN DAMAGE}

L. Broderick ${ }^{1}$,W. H. Chen ${ }^{2}$, R. Levy ${ }^{3}$, A. Foster ${ }^{1}$, C. Umanzor ${ }^{1}$, D. Chauhan ${ }^{4}$. ${ }^{1}$ QualityMetric, Johnston, RI, United States of America; ${ }^{2}$ GlaxoSmithKline, Value Evidence and Outcomes, Collegeville, PA, United States of America; ${ }^{3}$ GlaxoSmithKline, Global Medical Affairs, Collegeville, PA, United States of America; ${ }^{4}$ GlaxoSmithKline, Value Evidence and Outcomes, Brentford, Middlesex, United Kingdom

Background: Systemic lupus erythematosus (SLE) is a chronic, multisystem, autoimmune disease resulting in increased morbidity and mortality and reduced health-related quality of life (HRQoL). Patients with SLE are at risk of developing irreversible long-term organ damage (LTOD) caused by both disease activity and cumulative medication toxicities. Data regarding the overall disease burden and impact of LTOD in patients with SLE are limited.

Objectives: The primary objective of this qualitative study was to develop a conceptual model to describe the burden experienced by patients with SLE and LTOD. Methods: This study (GSK Study 209754) was conducted in three phases. First, a targeted literature review was performed to aid the development of an initial draft conceptual model. Key opinion leaders (KOLs) with experience in SLE and LTOD were then interviewed to assess the clarity, language, comprehensibility, and potential use of the conceptual model, and to help shape the patient interview materials. Finally, oneon-one interviews were performed with patients with SLE and LTOD in any of the 12 organ areas (defined by the Systemic Lupus International Collaborating Clinics/American College of Rheumatology Damage Index [SDI]), to gather patient perspectives on the common symptoms, functional impacts, treatment experiences, and HRQoL factors associated with LTOD. Data from the interviews were coded and analysed using NVivo software to identify patterns in responses concerning the key concepts of the overall patient burden of LTOD, and used to identify concepts to include in the model. Results: The literature review produced the preliminary conceptual model of LTOD. Results of the KOL interviews ( $n=5$ clinicians and $n=1$ patient advocate) indicated that the preliminary conceptual model broadly captured the patient experience of LTOD. KOLs emphasised the difference between SLE activity (flares) and LTOD; the conceptual model was subsequently updated in accordance with these recommendations. Interviews conducted with patients with confirmed single $(n=9)$ and multiple LTOD $(n=31)$ indicated that the burden of LTOD associated with SLE was more severe, debilitating, and life threatening than that caused by SLE flares. Almost all patients (39/40) reported aspects of their lives that were more severely affected since their LTOD diagnosis. All 40 patients reported LTOD-related physical impacts, which often affected patients' ability to perform everyday tasks. The most frequent physical impacts reported were a loss of vitality (39/40), long-term complications (e.g. unstable blood pressure, extreme pain, poor mobility, inflammation, dialysis, infection; 36/40), and severe fatigue (29/40). Cognitive impairments that became more pronounced after their LTOD diagnosis were reported by $27 / 40$ of patients. Typically characterised as "brain fog", these impairments were described as slower cognitive processing, forgetfulness, confusion, and aphasia. Economic impacts associated with LTOD included patients' inability to work (31/40), costs of care (33/40), and non-medical-related costs (17/30). Psychosocial impacts reported by patients with LTOD affected their emotional state (39/40), ability to socialise (40/40) and relationships (30/40). Additionally, 30/40 patients reported symptoms as more severe since their LTOD diagnosis, including pain (14/40), fatigue (9/40), and oedema $(8 / 40)$. Patients' treatment goals were largely aligned with their experienced impacts of LTOD, including managing the disease and symptoms (25/40), limiting further organ damage (15/40), and improving HRQoL (11/40)

Conclusion: The findings from this research clearly indicate that the patient burden of LTOD far surpasses that of SLE without LTOD. These data were incorporated and refined into a conceptual model that fully represents the patient experience of LTOD. The model will help researchers, clinicians, and patients to better understand the impact of SLE-related LTOD progression.

Funding: GSK

Acknowledgements: Medical writing assistance was provided by Casmira Brazaitis, PhD, Fishawack Indicia Ltd., UK, part of Fishawack Health, and was funded by GSK.

Disclosure of Interests: Lynne Broderick Consultant of: GSK, Wen-Hung Chen Shareholder of: GSK, Employee of: GSK, Roger Levy Shareholder of: GSK, Employee of: GSK, April Foster Consultant of: GSK, Cindy Umanzor Consultant of: GSK, Deven Chauhan Shareholder of: GSK, Employee of: GSK DOI: 10.1136/annrheumdis-2021-eular.1907

\begin{tabular}{|l|l}
\hline POS0740 & EPIDEMIOLOGY AND CLINICAL FEATURES OF \\
& OCULAR SARCOIDOSIS. STUDY OF 65 PATIENTS \\
& OF A SERIES OF 384 PATIENTS FROM A SINGLE \\
& UNIVERSITY HOSPITAL
\end{tabular}

C. Álvarez-Reguera ${ }^{1}$, J. J. Gaitán-Valdizán ${ }^{2}$, R. Fernández-Ramón², R. Demetrio-Pablo², J. L. Martín-Varillas ${ }^{3}$, L. Sanchez-Bilbao ${ }^{1}$,
D. Martínez-López ${ }^{1}$, I. González-Mazón ${ }^{1}$, M. Á. González-Gay ${ }^{1}$, R. Blanco ${ }^{1}$. ${ }^{1}$ Hospital Universitario Marqués de Valdecilla, Rheumatology, Santander, Spain; ${ }^{2}$ Hospital Universitario Marqués de Valdecilla, Ophthalmology, Santander, Spain; ${ }^{3}$ Hospital de Sierrallana, Rheumatology, Santander, Spain

Background: Ocular involvement in sarcoidosis can be present in up to $80 \%$ of patients. If not treated, it can lead to significant visually complications (1-5). Objectives: Our aim was to assess the main a) epidemiology and b) clinical features of ocular sarcoidosis in a wide and unselected series from a single university hospital. Methods: Study of a large cohort $(n=384)$ of all consecutive patients diagnosed with sarcoidosis from January 1, 1999 to December 31, 2019. Finally, 344 patients were included according to the ATS/ERS/WASOG criteria (Eur Respir J. 1999;14:735-7). Results: 65 (33 men/32 women) of 344 (18.9\%) patients had ocular involvement. Mean age at diagnosis was $45.6 \pm 15.9$ years. The most frequent extraocular clinical clusters were respiratory ( $80 \%)$, osteoarticular $(30.8 \%)$ and cutaneous $(29.2 \%)$ (figure 1$)$. Ocular manifestations and complications are shown in table 1. Uveitis $(83.1 \%)$, orbital lesions (7.7\%) and retinal vasculitis (6.2\%) were the most common ocular lesions. Median Best Corrected Visual Acuity (BCVA) at diagnosis and after one year of follow-up was 0.6 [0.3-0.8] and 0.9 [0.30-1], respectively. Retinal vasculitis was associated to the worst BCVA outcome, and panuveitis to more frequent and severe complications.

Conclusion: Ocular manifestations, especially uveitis, are frequent in sarcoidosis. A more aggressive and early treatment may be indicated in panuveitis and retinal vasculitis.

\section{REFERENCES:}

[1] Riancho-Zarrabeitia L, et al. Semin Arthritis Rheum 2015;45:361-8.

[2] Riancho-Zarrabeitia L et al. Clin Exp Rheumatol 2014; 32:275-84.

[3] Vegas-Revenga N, et al. Am J Ophthalmol 2019; 200:85-94.

[4] Calvo-Río V, et al. Clin Exp Rheumatol 2014; 32 (4 Suppl 84): S54-7. Epub 2014 Jul 8.

[5] Cordero-Coma et al. Mediators Inflamm. 2014; 2014:717598.

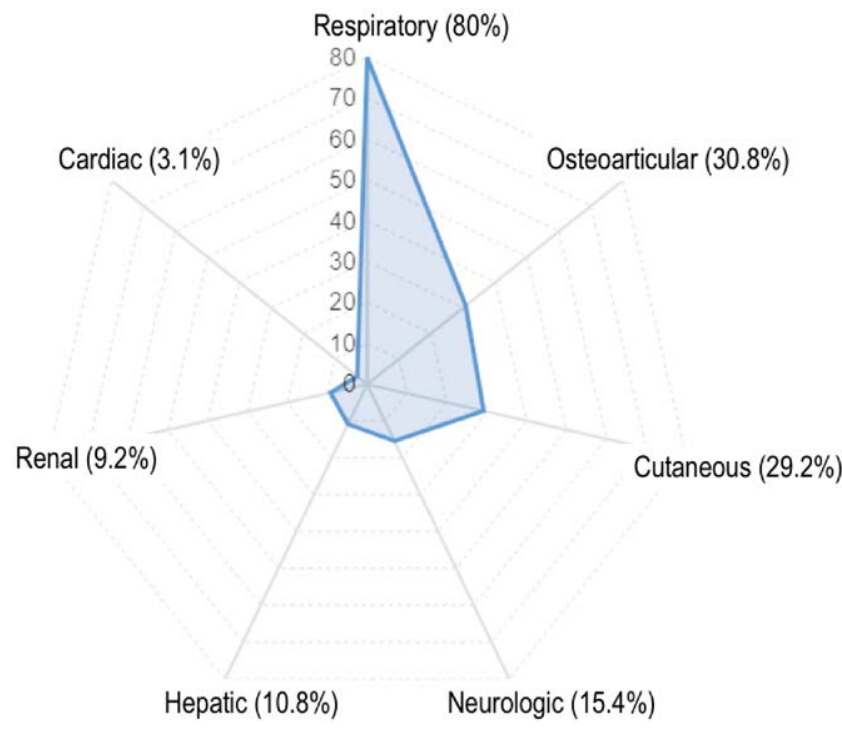

Figure 1. Clinical clusters of associations in ocular sarcoidosis.

Table 1. Ocular manifestations and associated complications after 1 year of follow-up of 65 patients with ocular sarcoidosis.

\begin{tabular}{|c|c|c|c|c|c|c|c|c|}
\hline $\begin{array}{l}\text { Type of } \\
\text { ocular } \\
\text { affectation }\end{array}$ & N (\%) & $\begin{array}{c}\text { Median } \\
\text { BCVA at } \\
\text { onset } \\
\text { [IQR] }\end{array}$ & $\begin{array}{c}\text { Median } \\
\text { BCVA afte } \\
1 \text { year of } \\
\text { follow-up } \\
\text { [IQR] }\end{array}$ & $\begin{array}{l}\text { Cataract } \\
\text { r N (\%) }\end{array}$ & $\begin{array}{c}\text { OP } \\
\mathrm{N}(\%)\end{array}$ & $\begin{array}{l}\text { OHT } \\
\text { N (\%) }\end{array}$ & $\begin{array}{l}\text { CME } \\
\text { N (\%) }\end{array}$ & $\begin{array}{l}\text { ERM } \\
N(\%)\end{array}$ \\
\hline
\end{tabular}

Uveitis, pattern 54 (83.1) 0.6 [0.3-0.8] 0.9 [0.6-1] 18 (27.7) 11 (16.9) 7 (10.8) 7 (10.8) 8 (12.3) $\begin{array}{llllllllll}\text { Anterior } & 31(47.7) & 0.7[0.3-0.8] & 0.8[0.5-1] & 13(41.9) & 2(6.5) & 2(6.5) & 2(6.5) & 2(6.5)\end{array}$

Panuveitis $\quad 16(24.6) \quad 0.4[0.2-0.7] \quad 0.9[0.5-1] \quad 5(31.3) \quad 7(43.8) \quad 4(25) \quad 5(31.3) 5(31.3)$

$\begin{array}{lllllllll}\text { Posterior } & 5(5.2) & 0.5[0.1-0.9] & 0.9[0.9-1] & 0 & 2(40) & 1(20) & 0 & 0\end{array}$

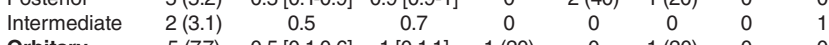

$\begin{array}{lllllllll}\text { Orbitary } & 5(7.7) & 0.5[0.1-0.6] & 1[0.1-1] & 1(20) & 0 & 1(20) & 0 & 0\end{array}$ $\begin{array}{lllllllll}\text { Retinal } & 4(6.2) & 0.6[0.5-0.8] & 1[0.6-1] & 0 & 0 & 0 & 0 & 1(25)\end{array}$

vasculitis

Dry eye

$\begin{array}{lcccccccc}\text { Scleritis } & 4(6.2) & 1 & 0.9 & 0 & 0 & 0 & 0 & 0 \\ & 1 & 0.6 & 1.0 & 0 & 0 & 0 & 0 & 0\end{array}$

Abbreviations: BCVA: Best corrected visual acuity; CME: Cystoid macular edema ERM: Epiretinal membrane; OP: Optic Papillitis; OHT: Ocular hypertension. 
Disclosure of Interests: Carmen Álvarez-Reguera: None declared, Jorge Javier Gaitán-Valdizán: None declared, Raúl Fernández-Ramón: None declared, Rosalía Demetrio-Pablo: None declared, José Luis Martín-Varillas: None declared, Lara Sanchez-Bilbao: None declared, David Martínez-López: None declared, Iñigo González-Mazón: None declared, Miguel Á. González-Gay Speakers bureau: Abbvie, Pfizer, Roche, Sanofi and MSD., Grant/research support from: Abbvie, MSD, Janssen and Roche., Ricardo Blanco Speakers bureau: Abbvie, Pfizer, Roche, Bristol-Myer, Janssen, Lilly and MSD., Grant/research support from: Abbvie, MSD and Roche.

DOI: 10.1136/annrheumdis-2021-eular.1930

\section{POS0741 HISTOPATHOLOGIC PATTERNS OF LUPUS NEPHRITIS PREDICT THE RISKS OF MORTALITY A SINGLE-CENTER RETROSPECTIVE STUDY}

$\underline{\text { Y. W. Liao }}^{1}$, W. T. Hung ${ }^{1}$, Y. M. Chen ${ }^{1}$, C. W. Hsieh ${ }^{1}$, T. Y. Hsieh ${ }^{1}$, Y. H. Chen ${ }^{1}$, W. N. Huang'. ' Taichung Veterans General Hospital, Division of Allergy, Immunology and Rheumatology, Taichung, Taiwan, Republic of China

Background: Lupus nephritis is a significant complication of systemic lupus erythematosus and is associated with increased risks of end-stage kidney disease and mortality.

Objectives: The retrospective observational study aims to investigate which component of the National Institutes of Health activity and chronic indices of lupus nephritis can predict mortality.

Methods: We identified 528 SLE patients with biopsy-proven lupus nephritis between 2006 and 2019. Two patients with class VI lupus nephritis were excluded, and a total of 526 patients were analyzed. Serum creatinine, urine protein-to-creatinine ratio (UPCR), and serologic markers for SLE disease activity were measured at the time of the renal biopsy. The histopathologic findings of renal biopsies were classified by utilizing the International Society of Nephrology/ Renal Pathology Society (ISN/RPS) classification.

Results: Among 526 patients enrolled, 64 expired, and 44 were female $(68.8 \%, p=0.004)$. Class IV $( \pm V)$ comprised the most $(n=39,60.9 \%)$, followed by class $V(n=18,29.7 \%)$. Lower eGFR was observed in the death group, compared with the survival group (median: 24.7 vs. $80.5, p<0.001$ ). There were no significant differences in UPCR and serologic markers for SLE (dsDNA, C3, and C4). Total scores of chronicity index and the scores for each index were higher in the death group. Interestingly, although total scores of activity index in death and survival groups did not differ significantly, the scores for cellular crescents tended to be higher in the death group $(1.38 \pm 1.77$ vs. $0.72 \pm 1.24$, $\mathrm{p}=0.002$ )

In the univariable analysis, age, male sex, eGFR, activity index scores, cellular crescents, chronicity index scores, and all $\mathrm{Cl}$ components (global obsolete glomeruli, tubular atrophy, interstitial fibrosis, fibrous crescents) and tubulointerstitial nephritis were significantly associated with an increased risk of death. When patient characteristics and $\mathrm{NIH}$ activity/ chronicity indices were jointly examined in a multivariable analysis, fibrous crescents were significantly associated with increased risk of death in females (HR 5.23 [95\% Cl: 1.51, 18.09]) (Table 1). In males, the risks of death increased with cellular crescents (HR 1.73 [95\% $\mathrm{Cl}: 1.10,2.73])$ but decreased with global obsolete glomeruli $(\mathrm{HR} 0.12[95 \% \mathrm{Cl}$ : $0.02,0.91])$.

Conclusion: In this single-center observational study, fibrous crescents in females and cellular crescents in males were significantly associated with increased risks of mortality.

REFERENCES:

[1] Doria A, laccarino L, Ghirardello A, et al. Long-term prognosis and causes of death in systemic lupus erythematosus. Am J Med 2006; 119: 700-706.
[2] Faurschou M, Starklint H, Halberg P, Jacobsen S. Prognostic factors in lupus nephritis: diagnostic and therapeutic delay increases the risk of terminal renal failure. J Rheumatol. 2006;33(8):1563-1569.

[3] Chen YM, Hung WT, Liao YW, et al. Combination immunosuppressant therapy and lupus nephritis outcome: a hospital-based study. Lupus. 2019;28(5):658-666.

Disclosure of Interests: None declared

DOI: 10.1136/annrheumdis-2021-eular.2006

\section{\begin{tabular}{|l|l}
\hline POS0742 & SCREENING AND BIOINFORMATICS ANALYSIS \\
\hline
\end{tabular} OF HUB GENES AND PATHWAYS FOR PRIMARY SJÖGREN'S SYNDROME BASED ON GEO DATABASE}

T. Kong ${ }^{1}$, S. X. Zhang ${ }^{2,3,4}$, S. Song ${ }^{2,3,4}$, X. Sun ${ }^{1}$, C. Zheng ${ }^{1}$, S. Feng ${ }^{5}$, L. Cheng ${ }^{1}$, G. Shi ${ }^{6}$, X. Li ${ }^{2,3,4}$, P. F. He ${ }^{7}$, Q. Yu ${ }^{1,7} .{ }^{1}$ Shanxi Medical University, School of Management, Taiyuan, China; ${ }^{2}$ The Second Hospital of Shanxi Medical University, Department of Rheumatology, Taiyuan, China; ${ }^{3}$ Shanxi Li Xiaofeng Medical Groups, Department of Rheumatology, Taiyuan, China; ${ }^{4}$ Ministry of Education, Key Laboratory of Cellular Physiology at Shanxi Medical University, Taiyuan, China; ${ }^{5}$ Shanxi Medical University, School of Humanities and Social Sciences, Taiyuan, China; ${ }^{6}$ Shanxi Medical University, Basic Medical College, Taiyuan, China; ${ }^{7}$ Shanxi Medical University, Institute of Medical Data Sciences, Taiyuan, China

Background: Primary Sjögren's syndrome (pSS) is an autoimmune disease that featured as lymphoplasmacytic infiltration of the exocrine glands leading to sicca symptoms ${ }^{1}$. However, its underlying molecular mechanisms remain elusive.

Objectives: This study aims to identify differentially expressed genes (DEGs) and pathways associated with the progression of pSS using bioinformatics analysis and explore its pathogenesis.

Methods: The pSS-associated gene chip data set GSE66795 was obtained from the Gene Expression Omnibus (GEO) database, which included 131 cases of fully-phenotyped pSS patients' whole blood samples and 29 cases of control samples. DEGs were screened Using R software. Online tool Metascape ${ }^{2}$ was used to make Gene Ontology (GO) and KEGG pathway enrichment. The PPI network was performed using String database. Hub genes were identified by Cytoscape.

Results: A total of 108 DEGs were captured, including 101 up-regulated genes and 7 down-regulated genes. GO enrichment showed that these DEGs were primarily enriched in defense response to virus, response to interferon-gamma, regulation of innate immune response, response to interferon-beta, double-stranded RNA binding, response to interferon-alpha. KEGG pathway enrichment analysis showed these DEGs were principally enriched in Influenza A, RIG-I-like receptor signaling pathway, necroptosis, Staphylococcus aureus infection. Finally, 9 hub genes (STAT1, IRF7, OAS2, GBP1, OAS1, IFIT3, IFIH1, OAS3, DDX60) had highest degree value.

Conclusion: The findings identified molecular mechanisms and the key hub genes that may involve in the occurrence and development of pSS.

REFERENCES:

[1] Francois $\mathrm{H}$, Mariette $\mathrm{X}$. Renal involvement in primary Sjogren syndrome. Nat Rev Nephrol 2016;12(2):82-93. doi: 10.1038/nrneph.2015.174 [published Online First: 2015/11/17].

[2] Zhou Y, Zhou B, Pache L, et al. Metascape provides a biologist-oriented resource for the analysis of systems-level datasets. Nat Commun 2019;10(1):1523. doi: 10.1038/s41467-019-09234-6 [published Online First: 2019/04/05].

Table 1. Logistic regression of predictors for mortality in patients with lupus nephritis

\begin{tabular}{|c|c|c|c|c|c|c|c|c|c|}
\hline & \multicolumn{3}{|c|}{ Univariable } & \multicolumn{4}{|c|}{ Multivariable (Female) } & \multicolumn{2}{|c|}{ Multivariable (Male) } \\
\hline & $\mathrm{HR}$ & $95 \% \mathrm{Cl}$ & $p$ value & $\mathrm{HR}$ & $95 \% \mathrm{Cl}$ & $p$ value & $\mathrm{HR}$ & $95 \% \mathrm{Cl}$ & $p$ value \\
\hline Age & 1.03 & $(1.01-1.05)$ & 0.002 & 1.02 & $(0.98-1.07)$ & 0.267 & 1.01 & $(0.95-1.08)$ & 0.670 \\
\hline Male sex & 2.10 & $(1.23-3.55)$ & 0.006 & & & & & & \\
\hline UPCR & 1.02 & $(0.95-1.09)$ & 0.616 & & & & & & \\
\hline eGFR & 0.97 & $(0.96-0.99)$ & $<0.001$ & 0.99 & $(0.96-1.00)$ & 0.183 & 0.98 & $(0.96-1.00)$ & 0.086 \\
\hline Activity Index & 1.06 & $(1.01-1.11)$ & 0.027 & & & & & & \\
\hline Cellular crescents & 1.29 & $(1.12-1.50)$ & $<0.001$ & 1.03 & $(0.63-1.67)$ & 0.917 & 1.73 & $(1.10-2.73)$ & 0.017 \\
\hline Chronicity Index & 1.16 & $(1.07-1.26)$ & $<0.001$ & & & & & & \\
\hline global obsolete glomeruli & 1.37 & $(1.08-1.76)$ & 0.011 & 1.24 & $(0.55-2.77)$ & 0.606 & 0.12 & $(0.02-0.91)$ & 0.040 \\
\hline Tubular atrophy & 1.65 & $(1.28-2.13)$ & $<0.001$ & 0.41 & $(0.06-2.82)$ & 0.362 & 4.77 & $(0.30-75.32)$ & 0.267 \\
\hline Interstitial fibrosis & 1.71 & $(1.32-2.23)$ & $<0.001$ & 3.70 & (0.52-26.24) & 0.191 & 1.37 & $(0.07-27.40)$ & 0.837 \\
\hline Fibrous crescents & 2.38 & $(1.40-4.03)$ & 0.001 & 5.23 & $(1.51-18.09)$ & 0.009 & 0.00 & (0-extremely large) & 0.989 \\
\hline Tubulointerstitial nephritis & 1.70 & $(1.03-2.80)$ & 0.037 & & & & & & \\
\hline
\end{tabular}

